Copyright (C) 2016 by Academic Publishing House Researcher

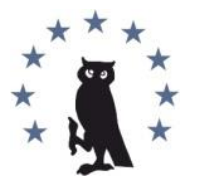

Published in the Russian Federation

European Researcher

Has been issued since 2010.

ISSN 2219-8229

E-ISSN 2224-0136

Vol. 106, Is. 5, pp. 271-281, 2016

DOI: 10.13187/er.2016.106.271

www.erjournal.ru

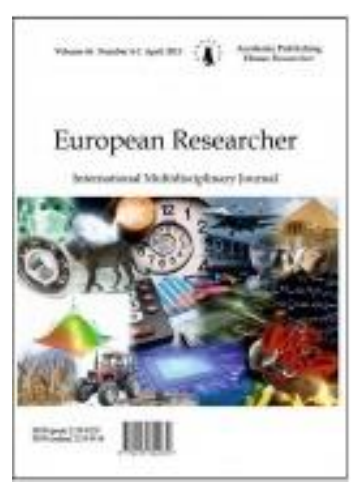

Philosophical sciences

Философские науки

UDC 1

\title{
Models and Laws of the Development of Scientific Knowledge
}

\author{
Sergey A. Lebedev
}

Bauman Moscow State Technical University, Russian Federation

5, 2-nd Baumanskaya, Moscow 105005

Doctor of Philosophy, Professor

E-mail: saleb@rambler.ru

\begin{abstract}
The problem of the dynamics of scientific knowledge is one of the central problems in modern methodology of science. This problem involves three main issues. The first concerns the essence of the process of science: whether it is a gradual evolutionary change( i.e. expansion of the scope and content of scientific truths), or describes a more complex model with jumps, revolutions, qualitative differences in views on the same subject [14]? This question may be formulated otherwise: is the dynamics of science the process of cumulative or, rather, anticumulative (including the waiver of some previous scientific views as unacceptable the position of new theories)? [7]. The second question concerns the explanation of the dynamics of scientific knowledge: whether it is possible to interpret it by appealing exclusively to action intrascientific (internal) factors or you must recognize a significant impact on scientific knowledge of a number of non-scientific (external), in particular, socio-cultural, factors? [16;19]. The third question involves the search for general laws of development of scientific knowledge and specific patterns of development of different fields of science [6]. The answers to the above-formulated problem cannot be obtained without the involvement of the factual material of the history of science. But the appeal to history of science assures us that the dynamics of scientific knowledge science is not a purely logical process of the unfolding of the content of scientific knowledge, and cognitive changes that take place in historical space and time. However, it is equally clear that historical material always needs some philosophical interpretation, as can be rationale reconstructs in different ways [15].

Keywords: scientific knowledge, scientific knowledge dynamics, models of development of scientific knowledge of laws of development of scientific knowledge.

\section{1. Кумулятивизм и антикумулятивизм}

История науки четко свидетельствует о том, что когнитивные изменения в науке, изменение содержания научного знания имеют эволюционный, то есть направленный и необратимый характер. Это означает, в частности, что неэвклидова геометрия не могла появиться раньше эвклидовой геометрии, а теория относительности и квантовая механика -
\end{abstract}


раньше или одновременно с классической механикой. Трактовать подобную закономерность можно по-разному. Например, индуктивистским образом, представляя процесс научного познания как постепенное накопление и последующее обобщение эмпирических фактов. В этом случае эволюция научного знания истолковывается как движение в сторону всё больших обобщений, а смена научных теорий понимается как замена менее общей теории более общей. Но тогда необходимо помнить, что на строгом языке логики понятие "степень общности" интерпретируется лишь экстенсивно. Это означает, что понятие $A$ считается более общим, чем понятие $B$, если и только если, все элементы объёма понятия $B$ входят в объём понятия $A$, но не наоборот.

Взгляд на теоретическое познание как на обобщение фактов, а на эволюцию научного знания как на увеличение степени общности сменяющих друг друга теорий - это, безусловно, индуктивистская интерпретация науки и её истории. Индуктивизм был господствующей концепцией в истории и философии науки вплоть до середины XX в. Одной из главных составляющих индуктивистской концепции динамики научного знания является так называемый принцип соответствия, согласно которому все положения предшествующей теории должны выводиться в качестве следствий из новой теории. В качестве примеров, подтверждающих принцип соответствия, обычно приводят либо соотношение классической механики и теории относительности, либо соотношение классической механики и квантовой механики, либо истолкование синтетической теории эволюции в биологии как синтеза дарвиновской концепции эволюции видов и генетики. Еще одним распространенным примером является индуктивистская трактовка соотношения эвклидовой и неэвклидовой геометрий. Такая трактовка динамики знания несомненно является кумулятивистской, согласно которой развитие научного знания является лишь прибавлением к старым научным истинам новых истин, которые ни в коем случае не отрицают прежние научные истины как ложные.

Однако при достаточно строгом логическом подходе к анализу соотношения старой и новой теории не обнаруживается такое отношение между ними, при котором предшествующая теория могла бы быть представлена в качестве частного или предельного случая сменившей ее новой теории. Рассмотрим, например, уравнение, связывающее значения массы и скорости в релятивистской механике: $\mathrm{m}=\mathrm{m} / \sqrt{ }\left(1-\mathrm{V}^{2} / \mathrm{c}^{2}\right) /[20]$.

где $m$ - масса движущегося тела; $m_{0}$ - масса покоящегося тела; $v$ - скорость движения тела; $c$ - скорость света. Это уравнение показывает, что с увеличением $v, m-$ возрастает, так как $\sqrt{ }\left(1-\mathrm{V}^{2} / \mathrm{c}^{2}\right)$ уменьшается. При $v=0, m=m_{o}$, но это лишь один случай, рассматриваемый в классической механике. Более того, только в одном её разделе - статике. При $v=c$ данное уравнение очевидно не имеет смысла. А ведь только при этих двух значениях $v$ можно было бы вывести в качестве частного случая значения массы в классической механике из уравнений значения массы этого тела в релятивистской механике.

Но если классическую механику нельзя представить как частный случай релятивистской механики, возможно, её следует трактовать как "предельный" случай последней. В принципе возможно, но хотя при последовательном уменьшении $v$ значение $m$ приближается к значению $m_{o}$, оно никогда его не достигает в полном соответствии с основополагающим принципом релятивистской механики. Поэтому $m_{o}$ не допускает интерпретации и в качестве предельного случая $m$. Дело в том, что может иметь место только одно из двух положений: либо масса тела меняет свою величину в процессе движения, либо нет. Классическая механика отрицает изменение массы тела в зависимости от скорости его движения или от скорости движения системы отсчета. Релятивистская же механика утверждает прямо противоположное. Таким образом, классическая и релятивистская механика теоретически, а потому и логически несовместимы друг с другом и, как показали постпозитивисты (Т. Кун и другие), могут быть вообще рассмотрены как не соизмеримые теории, поскольку у них нет общего нейтрального эмпирического базиса. Дело в том, что казалось бы одно и то же - массу, пространство, время - они описывают по-разному. Например, классическая механика исходит из того, что всегда можно одновременно задать точное значение двух переменных - координаты физического тела и его импульса. Квантовая механика, напротив, утверждает, что сделать это принципиально нельзя. Согласно принципу неопределённости Гейзенберга, существует предел точности 
одновременного определения этих сопряжённых величин, значение которого не может превышать величины постоянной Планка[2].

Аналогичные возражения можно привести и относительно других излюбленных примеров кумулятивистов. Например, синтетическая теория эволюции отнюдь не является механической (аддитивной) суммой положений аутентичной дарвиновской теории эволюции видов и менделевской генетики. Также не выдерживает критики принцип соответствия и применительно к вопросу о соотношении эвклидовой и неэвклидовых геометрий. Последние не являются обобщением эвклидовой геометрии, поскольку многие утверждения неевклидовой геометрий просто логически противоречат положениям эвклидовой геометрии. Например в эвклидовой геометрии через точку на плоскости по отношению к данной прямой можно провести только одну параллельную ей прямую линию, сумма углов любого треугольника в эвклидовой геометрии всегда равна 180є, отношение длины любой окружности к её диаметру в эвклидовой геометрии всегда равно $\pi$. В геометрии Лобачевского относительно тех же объектов утверждается прямо противоположное: через точку на плоскости к данной прямой можно провести более одной параллельной линии; что сумма углов любого треугольника всегда меньше $180^{*}$ и меняется от треугольника к треугольнику в зависимости от его размеров; что отношение длины окружности к ее диаметру величин переменная и всегда больше $\pi$. Положения же частной римановой геометрии противоречат как геометрии Эвклида, так и геометрии Лобачевского. В частной римановой геометрии утверждается, что через точку на плоскости по отношению к прямой нельзя провести ни одной параллельной ей прямой линии, что сумма углов любого треугольника всегда больше 180*, что отношение длины любой окружности к её диаметру всегда меньше $\pi$.

Противоречия между тремя названными геометриями можно устранить, если дополнительно ввести такой параметр, как кривизна непрерывной двумерной поверхности. Тогда утверждения геометрии Евклида оказываются верными для поверхностей с коэффициентом кривизны о, положения геометрии Лобачевского выполняются на двумерных поверхностях с постоянной отрицательной кривизной, а частная риманова геометрия описывает плоскости постоянной положительной кривизны. Поскольку в последних двух случаях коэффициент кривизны имеет одно из фиксированных значений (за исключением крайних) в континуальных интервалах $\{0, \ldots 1\}$ и $\{0, \ldots 1\}$, то возможна только одна эвклидова геометрия и бесконечное множество геометрий Лобачевского и Римана. Впоследствии Риман обобщил все эти случаи в построенной им общей римановой геометрии, где кривизна пространства представляет собой не постоянную, а переменную величину. Однако это чисто формальное обобщение, никак содержательно не влияющее на решение вопроса о соотношении эвклидовой и неэвклидовых геометрий и не отменяющее того факта, что геометрия Евклида не является частным случаем ни геометрии Лобачевского, ни геометрии Римана, так как последние неприменимы при описании поверхностей с коэффициентом кривизны, равным нулю.

Истолковать эвклидову геометрию как предельный случай неэвклидовых геометрий также нельзя. Конечно, можно сказать, что плоскость Эвклида является пределом внутренней или внешней поверхности шара, но с таким же правом можно утверждать, что эвклидова прямая есть предельный случай треугольника Лобачевского, а эвклидова окружность - предельный случай треугольника Римана. Утверждения такого рода являются столь же бессодержательными, сколь и нестрогими. Понятие "предельный случай" призвано скрыть качественное различие между явлениями. При желании любой феномен может быть назван "предельным случаем" любого другого феномена - метафоричность и не строгость используемых понятий это вполне допускает[9].

Таким образом, принцип соответствия не позволяет построить адекватную реконструкцию эволюции научного знания, a опирающийся на данный принцип кумулятивистская модель динамики науки с философской точки зрения фактически представляет собой редукционистскую трактовку развития науки, отрицающую возможность в ходе динамики научного знания осуществления качественных скачков в развитии его содержании. Но только признавая наличие таких качественных скачков, можно говорить не просто об эволюции, но и о развитии научного знания, о революциях 
в развитии научного знания, когда новые научные теории ставят под сомнение истинность старых теорий, поскольку несовместимы с ними по целому ряду утверждений о свойствах и отношениях объектов одной и той же предметной области[5].

Пытаясь развести старую и сменяющую ее новую теории по различным предметным сферам и считая при этом каждую из них истинной в своей области, многие явно лукавят, выдавая желаемое за действительное. Заявляя, что классическая механика описывает движение физических тел с большими массами и малыми скоростями, тогда как релятивистская - движение малых масс с большими скоростями, сторонники кумулятивизма никогда точно не определяют, какие массы и скорости следует считать "большими", а какие «малыми»; кроме того, они незаконно абстрагируются от того обстоятельства, что релятивистские эффекты либо имеют место при любых скоростях, либо вообще не возникают. Тот факт, что при малых скоростях релятивистский эффект значительно меньше, чем при больших, и для простоты практических расчётов этим эффектом можно пренебречь, отнюдь не устраняет фундаментального различия двух теорий, поскольку пренебречь чем-то не означает отказать ему в существовании.

В то же время необходимо подчеркнуть, что несовместимость старой и новой научной теории всегда является не полной, а лишь частичной. Во-первых, содержание таких теорий во многом может совпадать, во-вторых, ряд понятий в них имеет одинаковую интерпретацию (например, «масса» и в классической и в релятивистской физике трактуется как мера инерции; прямая линия и в эвклидовой и в неэвклидовой геометрии - как кратчайшее расстояние между двумя точками и т.д.). А это значит, что старая и новая теории могут быть частично соизмеримы. Как бы то ни было, более поздние теории, хотя и не полностью отрицают содержание предшествующих им теорий, однако в целом предлагают новое видение одной и той же предметной области.

Из всего сказанного выше можно заключить, что развитие научного знания представляет собой процесс, характеризующийся не только периодами кумулятивного развития, когда имеет место процесс методологически регулируемого процесса научного познания, но и качественными скачками, когда этот процесс прерывается. Поэтому в целом процесс развития научного знания не является некумулятивным [5; 15].

\section{2.Интернализм и экстернализм}

По вопросу о движущих силах развития научного знания в историографии науки и современной философии науки радикально также противостоят друг другу две взаимоисключающие позиции - интернализм и экстернализм [1; 12].

Согласно интерналистской точке зрения, развитие научного знания целиком детерминируется имманентно присущими науке ее внутренними целями, средствами и закономерностями. Интерналисты полагают, что научное знание должно рассматриваться как саморазвивающаяся система, содержание которой не зависит от социокультурных условий её бытия, от степени развитости социума и особенностей различных его подсистем экономики, политики, философии, религии, искусства, технической среды и т.д. В этом отношении интернализм, который оформился как четко отрефлексированная философская позиция лишь в 30-е годы XX в., считает своим основным философским противником экстерналистов, которые настаивают на фундаментальной роли социальных факторов не только на этапе возникновения науки, не только на стадии научных революций, но и на эволюционных этапах её развития. Среди наиболее видных представителей интернализма необходимо отметить таких историков науки как А. Койре[3], Р. Холл, П. Росси, Г. Герлак, а также таких популярных философов науки второй половины 20 века, как И. Лакатос и особенно К. Поппер. Пожалуй, именно Попперу принадлежит наиболее значительная попытка онтологического обоснования правомерности интерналистского подхода [14]. В онтологической концепции Поппера мир научного знания объявляется относительно самостоятельной объективной реальностью, все изменения в которой полностью предопределены только её внутренними возможностями и предшествующим состоянием. Как и другие интерналисты, Поппер не отрицает влияния на динамику научного знания социальных условий (меры востребованности обществом научного знания как средства решения различных проблем, влияния на науку различных вненаучных форм знания и т.д.), однако считает это влияние социума на науку чисто внешним, никак не затрагивающим 
само содержание научного знания.

Существуют две основные версии интернализма - эмпиризм и рационализм. В рамках эмпиризма главной движущей силой развития научного знания является нахождение (установление, открытие) новых фактов, а теории трактуются по отношению к фактам как нечто вторичное, задачей которых является исключительно систематизация и обобщение фактов (классическим представителем эмпиристского интернализма в историографии науки был, например, Дж. Гершель). Сторонники же рационалистической версии интернализма (Р.Декарт, Г. Гегель, К.Поппер и другие) считают, что основу динамики научного знания составляет не накопление фактов, а теоретические новации, которые по своей сути всегда есть результат либо когнитивного творчества (отсюда акцент на роли индивидуальных способностей отдельных учёных, их продуктивного воображения, таланта и т.п.), либо перекомбинации уже имеющихся идей (когда прежние несущественные идеи становятся существенными, независимые - зависимыми, объясняемые - объясняющими и др.). Так или иначе, но любой вариант рационалистского интернализма включает в себя в качестве значимых концепций интеллектуальный преформизм и априоризм, согласно которым всё возможное содержание знания уже предзадано некоторой совокупностью базисных идей[4]. Научные же наблюдения трактуются в рационалистическом варианте интернализма лишь в качестве одного из внешних факторов, запускающих механизм мыслительного творчества и образования таких новых теорий, которые были бы более адекватны, чем прежние по отношению к познаваемым объектам.

Оценивая эвристический потенциал интерналистской парадигмы в целом, необходимо отметить такие её положительные черты, как выделение (хотя и граничащее с гипостазированием) качественной специфики научного знания по сравнению с вненаучными видами познавательной деятельности, преемственности в динамике научного знания, нацеленности научного познания на поиск объективной истины. К отрицательным чертам интернализма относятся: имманентизм (отрицание существования иных, помимо внутринаучных, факторов развития научного знания), явная недооценка социальной, исторической и субъективной природы научного познания, игнорирование его культурной и экзистенциальной мотивации, непонимание предпосылочного (идеализирующего и идеологического) характера любых теоретических построений, в том числе и собственной (интерналистской) модели развития научного знания.

В противоположность интерналистам, экстерналисты считают, что основным источником научных инноваций, определяющим не только направление, темпы развития, но и содержание научного знания, являются социальные потребности и культурные ресурсы общества, его материальный и духовный потенциал, а не сами по себе новые эмпирические данные или имманентная логика развития научного знания. С точки зрения экстерналистов в науке познавательный интерес - познание ради умножения и совершенствования знания в соответствии с неким универсальным методом - не имеет самодовлеющего значения. Познавательный интерес, в конечном счёте, всегда ограничивается и детерминируется определённым практическим интересом, социально обусловленной необходимостью найти решение той или иной важной проблемы: инженерной, технической, технологической, экономической, социально-гуманитарной.

Первая мощная попытка реализации экстерналистской программы в истории науки была предпринята в 1930-е годы (Б. Гессен, Дж. Бернал, Э. Цильзель, Д. Нидам и другие), вторая - в 1970-е годы (Т. Кун, П. Фейерабенд, М. Малкей, М. Полани, Л.А. Косарева, Г.Д. Гачев и другие)[4;12;16]. Необходимо отметить, что экстернализм уходит своими корнями еще в Новое время, когда произошло сближение научного теоретизирования с экспериментом, а научное познание стало позиционироваться как непосредственно связанное с ростом благополучия человека и совершенствованием средств, позволяющих человеку и обществу достичь могущества и власти над природой, - техники и орудий труда. Впоследствии обоснование научной деятельности как имеющей практическую природу, её зависимость от наличных социальных форм и практической деятельности составило одну из характерных черт и марксистской гносеологии (К. Маркс, В.И. Ленин, В.М. Шулятиков, А.А. Богданов, Д. Лукач, Т. Котарбинский и другие).

Будучи едины в признании существенного влияния общества и его потребностей на 
развитие научного знания, разные сторонники экстернализма расходятся в оценке значимости различных социальных факторов. В качестве главных факторов, определяющих развитие науки и научного знания, называются:

- экономические, технико-технологические потребности общества (Дж. Бернал, Б. Гессен и другие);

- тип социальной организации (А. Богданов);

- господствующая в обществе культурная доминанта (О. Шпенглер)[17];

- духовный потенциал общества (его философия, религия, искусство, нравственность, а также архетипы национального самосознания)[1];

- социокультурный фон науки, формирующийся на основании определённого типа взаимодействия всех указанных выше факторов (В.И. Купцов, С.Р. Микулинский и др.) [8; $10 ; 11]$;

• локальный социальный и социально-психологический контекст деятельности научных коллективов и отдельных учёных (Т. Кун, П. Фейерабенд, М. Малкей и др.). [4; 13].

Следующий вопрос, по которому расходятся экстерналисты, сводится к следующему: влияют ли социальные факторы только на направление и темпы развития науки или также на методологию и содержание научных теорий? Вплоть до 1970-х годов большинство экстерналистов отвечали положительно только на первую часть вопроса, считая, что содержание науки обусловлено исключительно содержанием познаваемого объекта и что наука располагает истинным методом, инвариантным по отношению к различным социальным условиям и применяющим его субъектам (доктрина социальной и ценностной нейтральности естествознания). Исключение делалось лишь для социальных и гуманитарных наук, в отношении которых признавалось существенное влияние социальных интересов и принимаемых учёными систем ценностей на их теоретические построения (Э. Дюркгейм, М. Вебер, К. Мангейм, Ю. Хабермас и другие). Однако развитие методологии, социологии и истории естествознания во второй половине XX в. привело к крушению представлений об инвариантности, всеобщности и объективности научного метода и научного этоса. В работах Т. Куна, П. Фейерабенда, М. Малкея, Л. Лаудана, представителей когнитивной социологии науки (С. Уолгар, Б. Барнс, К. Кнорр-Цетина и др.) убедительно показаны парадигмальность, партикулярность, ценностная обусловленность, историчность, конструктивность процесса познания в любой области науки[4;5;8]. Отсюда делается вывод о том, что только в рамках социологического и культурно-исторического подхода к развитию научного знания можно адекватно объяснить многие факты из истории науки. В частности, качественные скачки в развитии научного знания, амбивалентное и неуверенное поведение учёных в период научных революций, частичную несоизмеримость сменяющих друг друга теорий фундаментальных научных теорий во всех областях науки, плюрализм и конкуренцию научных гипотез, борьбу за приоритеты и признание в науке и др. Естественное и достаточно убедительное объяснение многих фактов такого рода несомненно составляет сильную сторону экстернализма. Вместе с тем, следование чисто зкстерналисткой модели динамики науки неизбежно оборачивается опасностью недооценки относительной самостоятельности и независимости науки от социальных условий и, как следствие, грозит переходом на позиции абсолютного релятивизма и субъективизма (П. Фейерабенд).

При решении вопроса о выборе между интерналистской и экстерналистской моделями динамики научного знания необходимо, прежде всего, различать "жёсткие" и "мягкие" варианты каждого из этих подходов. Жёсткие версии экстернализма и интернализма неприемлемы в одинаковой мере. Жёсткий экстернализм может быть вполне законно квалифицирован как аналог эволюционного ламаркизма в биологии (Поппер), согласно которому внешняя среда (в случае науки - социокультурная) детерминирует генетические изменения в биологических особях (в случае науки такого рода мутационными изменениями являются когнитивные инновации). Что касается последовательного интернализма, то он является аналогом биологического преформизма и поэтому также не удовлетворителен.

Конечно, ни один из социокультурных факторов в отдельности, ни даже социокультурная среда в целом не может однозначно детерминировать появление новой 
идеи. Всякая идея, как справедливо утверждают интерналисты, может "родиться" только от другой идеи. Роль социокультурной среды состоит лишь в том, что она способна провоцировать (или не провоцировать) рождение определённой идеи, создавая благоприятные или неблагоприятные условия ее утверждения, делая её появление более или менее вероятным. Между наукой и её социальным окружением существует отношение не детерминации, а скорее, кооперации и резонанса, когда только сильное созвучие внутринаучных и вненаучных факторов по-настоящему способствует не только рождению новой идеи, но ее принятию научным сообществом и обществом в целом. Наука по своей социально-биологической (адаптационной) природе потенциально в состоянии откликнуться на вызовы и требования среды, но при этом она может быть готова к этому не в достаточной степени. Развивая биологическую аналогию, выразим эту мысль следующим образом: чтобы родить какую-то идею, наука, прежде всего, должна быть уже беременной ею. Социальное же окружение может влиять на науку не обязательно непосредственно, но и через своих когнитивных посредников (историю науки, философию, искусство, обыденное знание и др.), не обязательно являющихся частью науки вообще. Как правило, не социальный фон в целом, а именно его когнитивная часть выступает посредствующим звеном, механизмом передачи науке вызова и потребностей социокультурной среды [19].

Если использовать синергетическую модель, социокультурную среду можно интерпретировать в качестве своеобразного контрольного параметра, оказывающего существенное влияние на эволюцию науки и научного знания, представляющих собой открытые, диссипативные и нелинейные системы. Важно, кроме того, понимать, что, так же как в ходе биологической эволюции мутирует не наследственная структура организма вообще, а наследственная структура конкретного организма, представителя определённого биологического вида, и в процессе развития научного знания мыслит не научное сознание само по себе, а отдельный учёный. Конечно, при экстерналистском подходе к динамике научного знания историк и философ науки значительно усложняют свою работу. Усложняют, но не обедняют реальный процесс научного познания. Интернализм же, представляя науку и научное познание абсолютно самостоятельными и независимыми системами знания по отношению к обществу и его потребностям, ориентирует историков на явно упрощённую картину развития научного знания. Поэтому интернализм в лучшем случае может быть достаточно адекватной теорией лишь внутринаучных составляющих эволюции научного познания [18].

Альтернативой как экстернализму, так и интернализму является диалектическая концепция единства и взаимосвязи внутринаучных (логико-эмпирических) и социокультурных факторов в развитии научного знания [10]. Конечно, необходимо помнить, что мера этой взаимосвязи для разных периодов истории науки и для разных случаев решения конкретных научных проблем весьма различна. Очевидно, что невозможно привести к общему знаменателю ситуацию, когда, например, создаётся новая фундаментальная теория, и ситуацию количественной обработки новых эмпирических данных по определенной методике или ситуацию вывода теорем из аксиом теории по определённым логическим правилам. Каждый раз, чтобы определить реальный вес внутринаучных и социокультурных факторов, требуется проводить конкретный анализ конкретной познавательной ситуации. Единообразно не нормированный характер единства внутринаучных и социокультурных факторов в процессе развития научного знания главный недостаток диалектической модели развития науки. В известной мере он является своеобразной платой за те большие и очевидные преимущества (антиаприоризм, историчность, полнота описания реальных познавательных ситуаций), которые диалектическая концепция динамики науки имеет по сравнению с интернализмом и экстернализмом. Очевидно, что любая эффективная теория развития научного знания должна уметь формулировать как общие закономерности этого развития, так и конкретизировать их применительно к различным областям науки. Опуская подробное теоретическое и историческое обоснование данного положения, попытаемся сформулировать как общие, так и специфические закономерности развития научного знания, вытекающие из диалектического понимания динамики научного знания [8; 10$]$. 
3. Общие и специфические закономерности развития научного знания

Среди общих закономерностей развития науки можно выделить следующие:

- детерминация ранее накопленным объёмом научного знания;

- прерывно-непрерывный характер эволюции [11];

- увеличение информационной ёмкости сменяющих друг друга научных теорий;

- $\quad$ эволюция научного познания от исследования относительно простых объектов к познанию всё более сложных;

- $\quad$ развитие научного знания в направлении все большей точности, доказательности и проверяемости;

- увеличение методологического и методического арсенала;

- усиление взаимосвязи объектной, практической, социокультурной и мировоззренческой детерминации научного знания;

- $\quad$ рост теоретического и методологического плюрализма научных построений;

- увеличение роли и значения когнитивных коммуникаций между учёными в процессе создания, оценки и проверки различных единиц научного знания;

- рост дифференциации научного знания и научных дисциплин;

- усиление интеграционных связей между различными областями научного знания;

- взаимопроникновение методов и концепций из разных областей науки;

- $\quad$ рост числа междисциплинарных, проблемных и комплексных исследований;

- увеличение значения творческого и личностного потенциала учёных в процессе создания и утверждения научных теорий;

- возрастание когнитивной ответственности учёных за принимаемые научные решения;

- усиление инновационной ориентированности научных концепций;

- стандартизация научного знания в качестве информационного продукта в процессе его включения в глобальную информационную сеть.

Наряду с этими общими законами развития научного знания в каждой из областей науки действуют специфические закономерности, обусловленные особенностями их предметного содержания и решаемыми задачами. Специфические закономерности развития научного знания в разных областях науки.

\section{Естествознание}

Специфическими закономерностями развития естественнонаучного знания являются:

- постоянное расширение предметной (объектной) сферы;

- рост объёма научных наблюдений и их точности;

- $\quad$ развитие экспериментальной базы и возрастание её роли как основы и критерия объективности и истинности естественнонаучного знания;

- увеличение веса и относительной самостоятельности теоретического знания по отношению к эмпирическому уровню;

- усиление математизации знания;

- рост системной организации всего естественнонаучного знания с выделением ведущей роли парадигмальных теорий и научной картины мира в обеспечении его целостности;

- усиление взаимосвязи и взаимодействия естественных наук с техническими, социальными и гуманитарными науками;

- рост ориентированности на решение фундаментальных экономических, практических и социальных проблем. знания:

Математика. Специфические закономерности развития математического

- усиление абстрактности математического знания;

- $\quad$ широкое использование логики и её методов в построении и обосновании теорий;

- рост разнообразия способов введения и построения математических объектов и теорий;

- обеспечение внутренней целостности знания, поиск единых оснований математики как науки;

- ормализация содержательных математических теорий и рассуждений; 
- конструктивизация, алгоритмизация и компьютеризация знания;

- усиление взаимосвязи математического знания со всеми другими науками (естествознанием, техническими и социальными науками);

- возрастающая степень ориентированности на решение фундаментальных научных, практических и социальных проблем.

Технические науки. Специфические закономерности развития знания в технических науках:

- кумулятивно-прерывный характер изменений технического знания;

- тесная взаимосвязь с естественными, социальными и военными науками;

- непосредственная связь с практикой, материальными интересами и потребностями общества;

- существенная зависимость от уровня и характера поддержки со стороны государства и частного бизнеса;

- соответствие технических и технологических проектов экологическим и гуманитарным требованиям;

- повышение уровня математизации и компьютеризации техники и технологий;

- усиление междисциплинарного и комплексного характера знания;

- развития знания от моделирования отдельных технических систем и технологических процессов к построению моделей сложных технических систем и моделированию эволюции техносферы в целом.

Социальные и гуманитарные науки. Специфическими закономерностями развития социально-гуманитарного знания являются:

- существенная мировоззренческо-ценностная детерминация;

- непосредственная зависимость от исторически изменчивого и противоречивого социокультурного контекста;

- плюрализм и диалогичность;

- рефлексивный и эмоционально-выразительный характер дискурса;

- использование всех лингвистических и семиотических средств в ходе изложения, обоснования и оценки социальных концепций;

- поддержание высокого уровня критичности дискурса;

- совершенствование герменевтических техник;

- высокая степень интенсивности когнитивных взаимодействий между членами профессионального сообщества;

- тесное взаимодействие с непрофессиональными читателями научных социальных и гуманитарных текстов.

\section{Выводы}

1.Развитие научного знания обусловлено как внутринаучными факторами (новые эмпирические данные, новые теоретические идеи), так и социокультурными факторами (практические потребности общества, социальный заказ, философские и мировоззренческие идеи и др.).Внутринаучные факторы являются основной движущей силой развития научного знания в эволюционные фазы истории науки, тогда как социокультурные факторы в периоды научных революций, а также в прикладных научных исследованиях [13; 15].

2. Интернализм абсолютизируюет роль внутринаучных факторов в развитии научного знания, тогда как экстернализм абсолютизирует роль социокультурных факторов. Наиболее адекватной реальной истории науки представляется концепция единства внутринаучных и социокультурных факторов как одинаково необходимых и значимых детерминант динамики научного знания [3;11].

3.Развитие научного знания в целом является непрерывно-прерывным процессом. Он является непрерывным на эволюционной стадии развития и прерывным во время научных революций, когда происходит смена фундаментальных теорий [10; 11]. Кумулятивистская модель динамики науки абсолютизирует момент непрерывности в развитии научного знания, тогда как антикумулятивистская - момент прерывности.

4.Смена старых теорий новыми представляет собой не полное отрицание содержания прежних теорий, а лишь частичное. Вместе с тем, поскольку многие положения новых 
теорий противоречат старым, постольку принцип соответствия не является адекватным описанием отношения старой фундаментальной теорий и новой. Преемственность между ними имеет место, однако она имеет не формально-логический, а диалектический характер [21].

5. В развитии научного знания наряду с общими закономерностями развития в каждой области науки действуют и специфические закономерности, обусловленные особенностями их содержания и функций в общей системе научного знания [20].

\section{Благодарности}

Работа выполнена при поддержке гранта 16-23-01004"a(m)" РГНФ-БФФИ «Философско-методологические и естественнонаучные основания современных биологических и экологических концепций».

\section{Примечания:}

1. Гайденко П.П. Эволюция понятия науки. М., 2010.

2. Гейзенберг В. У истоков квантовой теории. М., 2004.

3. Койре А. Очерки истории философской мысли. М., 1985.

4. Косарева Л.М. Социокультурный генезис науки Нового времени. М., 1989.

5. Кун Т. Структура научных революций. М., 2001.

6. Лебедев С.А. Философия науки: общие проблемы. М.: Издательство Московского университета. 2012. $336 \mathrm{c.}$

7. Лебедев С.А. Основные модели развития научного знания//Вестник Российской академии наук. 2014.Т.84. №6. С.506. C. 53-64.

8. Лебедев С.А. Пересборка эпистемологического//Вопросы философии. 2015. №.6.

9. Лебедев С.А. Научная картина мира в ее развитии //Вестник Московского университета, Серия 7: Философия. 2012. №3. С.3-27.

10. Лебедев С.А. Основные положения позитивно-диалектической парадигмы эпистемологии и философии науки //Новое в психолого-педагогических исследованиях. 2014. №3. С. 7-13.

11. Лебедев С.А. Культурно-исторические типы науки и закономерности ее развития // Новое в психолого-педагогических исследованиях. 2013. № 3. С. 7-18.

12. Малкей М. Наука и социология знания. М., 1983.

13. Мамчур Е.А. Проблемы социокультурной детерминации научного знания. М., 1987.

14. Поппер К. Логика и рост научного знания. М., 1983.

15. Принципы историографии естествознания. XX век. СПб, 2001.

16. Социокультурный контекст науки. М., 1998.

17. Степин В.С. Философская антропология и история науки. М., 1992.

18. Структура и развитие науки. М., 1978.

19. Традиции и революции в развитии науки. М., 1991.

20. Lebedev S.A. The main models of development of scientific knowledge//Herald of the Russian Academy of Science. 2014. T.84. № 3. C. 201-207.

21. Lebedev S.A., Lebedev K.S. The global scientific revolution and its laws//Вопросы философии и психологии. 2014. № 1(1). С. 21-29.

\section{References:}

1. Gajdenko P.P. Jevoljucija ponjatija nauki. M.,2010.

2. Gejzenberg V. U istokov kvantovoj teorii. M., 2004.

3. Kojre A. Ocherki istorii filosofskoj mysli. M., 1985.

4. Kosareva L.M. Sociokul'turnyj genezis nauki Novogo vremeni. M., 1989.

5. Kun T. Struktura nauchnyh revoljucij. M., 2001.

6. Lebedev S.A. Filosofija nauki: obshhie problemy. M.: Izdatel'stvo Moskovskogo universiteta. 2012. $336 \mathrm{~s}$.

7. Lebedev S.A. Osnovnye modeli razvitija nauchnogo znanija//Vestnik Rossijskoj akademii nauk. 2014.T.84. №6. S.506.

8. Lebedev S.A. Peresborka jepistemologicheskogo //Voprosy filosofii. 2015. №.6. S.53-64. 
9. Lebedev S.A. Nauchnaja kartina mira v ee razvitii //Vestnik Moskovskogo universiteta, Serija 7: Filosofija. 2012. №3. S.3-27.

10. Lebedev S.A. Osnovnye polozhenija pozitivno-dialekticheskoj paradigmy jepistemologii i filosofii nauki //Novoe v psihologo-pedagogicheskih issledovanijah. 2014. №3. S. 7-13.

11. Lebedev S.A. Kul'turno-istoricheskie tipy nauki i zakonomernosti ee razvitija//Novoe v psihologo-pedagogicheskih issledovanijah. 2013. № 3. S. 7-18.

12. Malkej M. Nauka i sociologija znanija. M., 1983.

13. Mamchur E.A. Problemy sociokul'turnoj determinacii nauchnogo znanija. M., 1987.

14. Popper K. Logika i rost nauchnogo znanija. M., 1983.

15. Principy istoriografii estestvoznanija. XX vek. SPb, 2001.

16. Sociokul'turnyj kontekst nauki. M., 1998.

17. Stepin V.S. Filosofskaja antropologija i istorija nauki. M., 1992.

18. Struktura i razvitie nauki. M., 1978.

19. Tradicii i revoljucii v razvitii nauki. M., 1991.

20. Lebedev S.A. The main models of development of scientific knowledge//Herald of the Russian Academy of Science. 2014. T.84. №3. C. 201-207.

21. Lebedev S.A., Lebedev K.S. The global scientific revolution and its laws// Voprosy filosofii i psihologii. 2014. № 1(1). S. 21-29.

УДК 1

\section{Модели и закономерности развития научного знания}

\section{Сергей Александрович Лебедев}

МГТУ им. Н.Э. Баумана, Российская Федерация

Доктор философских наук, профессор

E-mail: saleb@rambler.ru

Аннотация. Проблема динамики научного знания является одной из центральных в современной методологии науки. Эта проблема включает в себя три главных вопроса. Первый касается сущности процесса развития науки: представляет ли он собой постепенное эволюционное изменение, то есть расширение объёма и содержания научных истин, или должен описываться более сложной моделью: со скачками, революциями, качественными отличиями во взглядах на один и тот же предмет? Этот вопрос можно сформулировать и иначе: является ли динамика науки процессом чисто кумулятивным ( накопительным) или антикумулятивным (включающим отказ от некоторых прежних научных взглядов как неприемлемых с позиции новых теорий)? Второй вопрос связан с бифуркацией в объяснении динамики научного знания: можно ли интерпретировать её, апеллируя исключительно к действию внутринаучных факторов, или необходимо признать существенное влияние на научное знание также ряда вненаучных, в частности социокультурных, факторов? Третий вопрос предполагает поиск, как общих закономерностей развития научного знания, так и специфических закономерностей развития различных областей науки. Ответы на сформулированные выше проблемы нельзя получить без привлечения фактического материала из истории науки. Но обращение к истории науки убеждает нас в том, что динамика научного знания науки это не чисто логический процесс разворачивания содержания научного знания, а когнитивные изменения, совершающиеся в историческом пространстве и времени. Впрочем, столь же очевидно, что исторический материал всегда нуждается в некоторой философской интерпретации и может быть "рационально реконструирован" различным образом.

Ключевые слова: научное знание, динамика научного знания, модели развития научного знания, закономерности развития научного знания. 